International Journal of Clinical Pharmacology \& Toxicology (IJCPT)

ISSN 2167-910X

\title{
Steady State Plasma Levels of Bupropion After Administration of 3x150 Mg Extended Release Reference Tablets and Switching to 1x450 Mg Extended Release 450ER Tablets
}

Nadine Paiement ${ }^{1 *}$, Patrick K. Noonan $\mathrm{PhD}^{2}$, Mario A. González ${ }^{3}$, Horst Zerbe ${ }^{1}$

Review Article

${ }^{1}$ Intelgenx Corp. 6425 Abrams Saint-Laurent, Qc H4S 1X9 Canada.

${ }^{2}$ PK Noonan \& Associates, LLC Richmond, VA, USA.

${ }^{3}$ PK Kinetics International, Inc. Pembroke Pines, FL 33027, USA.

\section{Abstract}

In order to provide patients who take $450 \mathrm{mg}$ /day bupropion hydrochloride for the treatment of severe depressive disorder with a safe and convenient alternative to currently existing dose regimens, a high-dose bupropion ER tablet formulation containing $450 \mathrm{mg}$ of bupropion hydrochloride was developed. The results of the single dose pharmacokinetic study demonstrated bioequivalence of the $450 \mathrm{mg}$ ER tablet with three tablets of the $150 \mathrm{mg}$ strength taken at once, thus confirming that the $450 \mathrm{mg}$ tablet is safe and effective. In addition, the simulation of steady state bupropion plasma levels after administration of $3 \times 150 \mathrm{mg}$ bupropion ER fasting and subsequent switch to $1 \times 450 \mathrm{mg}$ bupropion ER fed confirm that even under "worst case conditions" patients who switch from 3x150 mg to 1x450 mg bupropion ER won't experience an elevated average $\mathrm{C}_{\max }$ and hence are not exposed to an increased risk of seizures.

Keywords: Bupropion; Pharmacokinetics; ER Formulation; Steady State; Simulations.

\section{*Corresponding Author:}

Nadine Paiement,

Intelgenx Corp. 6425 Abrams Saint-Laurent, Qc H4S 1X9 Canada.

E-mail: nadine@intelgenx.com

Received: September 17, 2012

Accepted: October 03, 2012

Published: October 16, 2012

Citation: Nadine Paiement (2012) Steady State Plasma Levels of Bupropion After Administration of 3x150 Mg Extended Release Reference Tablets and Switching to $1 \times 450 \mathrm{Mg}$ Extended Release 450ER Tablets. Int J Clin Pharmacol Toxicol. 1(1), 26-31. doi: http://dx.doi. org/10.19070/2167-910X-120005

Copyright: (C) 2012 Nadine Paiement. This is an open-access article distributed under the terms of the Creative Commons Attribution License, which permits unrestricted use, distribution and reproduction in any medium, provided the original author and source are credited.

\section{Introduction}

Bupropion extended release tablets are administered for the treatment of major depressive disorders. Initially, patients suffering from depression are commonly treated with lower doses and the daily dose is increased until the desired therapeutic effect is observed. Bupropion hydrochloride was initially developed as an immediate release tablet that was administered three-times per day. It was later developed into a twice a day tablet (Wellbutrin SR $®$ ) followed by a once-daily tablet (Wellbutrin XL ${ }^{\circledR}$ ) (3-4). Patients receiving the once-per-day bupropion product may require high daily doses; Bupropion $\mathrm{HCl}$ is approved for a maximum daily dose of $450 \mathrm{mg}$. However, because the commercial product is only available as 150 and $300 \mathrm{mg}$ tablets, patients requiring $450 \mathrm{mg}$ have to take multiples of the available lower strength tablets.

Bupropion hydrochloride $450 \mathrm{mg}$ extended-release tablets (450ER), was developed to allow patients to take one tablet as opposed to multiple tablets, hence eliminating the risk of an accidental dosing errors. In a single dose, three-period, three-treatment, cross-over study, it was demonstrated that 450ER (1 x $450 \mathrm{mg}$ tablet) was bioequivalent to REF (3 $\times 150 \mathrm{mg}$ tablets) when dosed in the fasting state. However, when 450ER tablets were administered with a standard high fat/ high calorie meal and compared to the fasting treatment, $\mathrm{C}_{\max }$ was bioequivalent but AUC increased slightly $(25 \%)$ and didn't meet the $80-125 \%$ bioequivalence (BE) confidence interval criteria (CI).

However, this increase of AUC after administration with food is routinely observed in bupropion extended-release products. REF shows a fed/fasting ratio of $110 \%$ (CI: 104-116\%) for AUC while $\mathrm{C}_{\max }$ was lower (point estimate: $92 \%$ ). Similarly, Aplenzin ${ }^{\circledR}$ (Bupropion hydrobromide extended-release tablets containing the same dose of bupropion as 450ER tablets), show a ratio fed/fasting of $107.48 \%$ (CI: $98.20-117.64 \%$ ) for $\mathrm{C}_{\max }$ and a ratio fed/fasting of $119.47 \%$ (CI: $113.23-126.06 \%)$ for $\mathrm{AUC}_{\tau}$ (5). Both products are labeled indicating that they may be taken with no regard to food or meal timing.

It is known from the history of bupropion $\mathrm{HCl}(1-2)$ that high $\mathrm{C}_{\text {max }}$ values may be linked to higher seizure risk. A reduction in the frequency of reported seizures occurred after the marketing transition from Bupropion immediate release to Bupropion twice a day and $\mathrm{Bu}-$ propion extended release (3). Thus, it was hypothesized that an increase in bupropion exposure with 450ER could result in an increase in the frequency of seizures. This concern was directed at those patients who would be switched from the current commercial bupropion $3 \times 150 \mathrm{mg}$ to $450 \mathrm{ER}$. PK modeling and simulation provide the context needed to compare these two oral formulations. Steady-state simulations may provide insight into the steady-state $\mathrm{PK}$ of bupropion in patients receiving REF tablets $(3 \times 150 \mathrm{mg})$ and who may be switched to the 450ER tablets (taken with food). One goal was to predict potential increases in steady-state $\mathrm{C}_{\max }$ or AUC values which might indicate that patients would experience a higher risk of developing seizures.

\section{Materials and Methods}

\section{Clinical studies}

Two single dose clinical studies form the basis of these simulations. The first study (Study 1) was a three-way cross over study in healthy volunteers comparing Forfivo XLTM 450mg (Bupropion hydrochloride 
extended-release tablets, 450ER, Edgemont Pharmaceutical LLC, manufactured by Pillar5 Pharma Inc. in Ontario Canada) under fasting and fed condition to Wellbutrin XL ${ } 3$ x 150 mg (REF, Glaxo Smith Kline Inc., Manufactured by DSM Pharmaceutical Inc. North Carolina, USA) under fasting condition only. This study was conducted on 36 healthy subjects. The second study (Study 2) was a four-way cross over comparing these same products both under fasting and fed conditions. This study was conducted on 20 healthy subjects, except the fed portion of REF which was conducted on 10 subjects. The protocols for both studies were reviewed and approved by investigational review boards. Bioanalyses for both studies were conducted using a validated LC/MS/MS procedure.

\section{Steady State Simulations}

Steady-state simulations were conducted to better understand the steadystate PK of bupropion in patients receiving REF (3x150 mg) and who may be switched to the 450ER tablets (taken with food). The goal was to predict potential increases in $\mathrm{C}_{\max }$ or $\mathrm{AUC}_{\tau}$ values which might indicate that patients would experience a higher risk of developing seizures.

Single dose of REF data generated in the four-way crossover showed a delayed $\mathrm{T}_{\max }$ and a lower $\mathrm{C}_{\max }$. This lower exposure would support a safer product since the assumption is that seizures are associated with elevated $\mathrm{C}_{\max }$. In keeping with this hypothesis, the published seizure rate for bupropion sustained-release formulations decreased to $0.1 \%$ at doses of up to $300 \mathrm{mg} /$ day (4).

Steady-state plasma concentration versus time profiles were simulated with the Nonparametric Superposition (NPS) feature within WinNonlin ${ }^{\circledR}$ Pro (Pharsight Corporation, St. Louis, MO) using individual single dose profiles obtained from the study 2. Steady-state plasma concentration-time profiles were simulated for each individual subject.

In order to assess the effect of switching patients from REF $3 \times 150 \mathrm{mg}$ to $450 \mathrm{ER}$, steady-state plasma concentration versus time profiles (after 8 daily doses) were simulated for each individual subject. These simulations included additional points beyond the last 8th dose in order to provide the concentrations $288 \mathrm{hrs}$. Single dose profiles for 450ER were simulated using NPS to allow manual superposition of these single dose profiles (Day 9) with the steady-state profiles (Days 8 to 9). Pharmacokinetic parameters were derived for each subject's simulated profile using noncompartmental modeling in WinNonlin Pro.

\section{Treatment Assumptions}

For the switch assessment (switching from REF $3 \times 150 \mathrm{mg}$ to $450 \mathrm{ER}$ on Day 9), it was assumed that REF steady-state was achieved by the 8th daily dose. A visual assessment of Panel A in Figure $1 \mathrm{~A}$ shows that steady-state was achieved by Days 3 or 4 validating the assumption of steady-state achievement by Day 8 .

\section{Biostatistical Evaluation}

To assess the equivalence of treatments, particularly after switching from REF $3 \times 150 \mathrm{mg}$ fasting to $450 \mathrm{ER}$ fed, $90 \%$ confidence intervals of the geometric means of the individual ratios of the simulated $\mathrm{C}_{\max }$ and $\mathrm{AUC}_{\tau}$ were calculated using the $\mathrm{BE}$ Wizard in WinNonlin Pro.

\section{Results and Discussion}

Figure $1 \mathrm{~A}$ illustrates the mean concentration-time profiles for $450 \mathrm{ER}$

Figure 1: Average simulated plasma bupropion concentrations after eight consecutive doses of each treatment (A) Average simulated steady-state plasma bupropion concentrations (B) and Simulated mean (SD) steady state plasma bupropion concentrations after administration of REF (fasting) for 8 Days with switch to 450ER (fed) on day 9 (C)

A

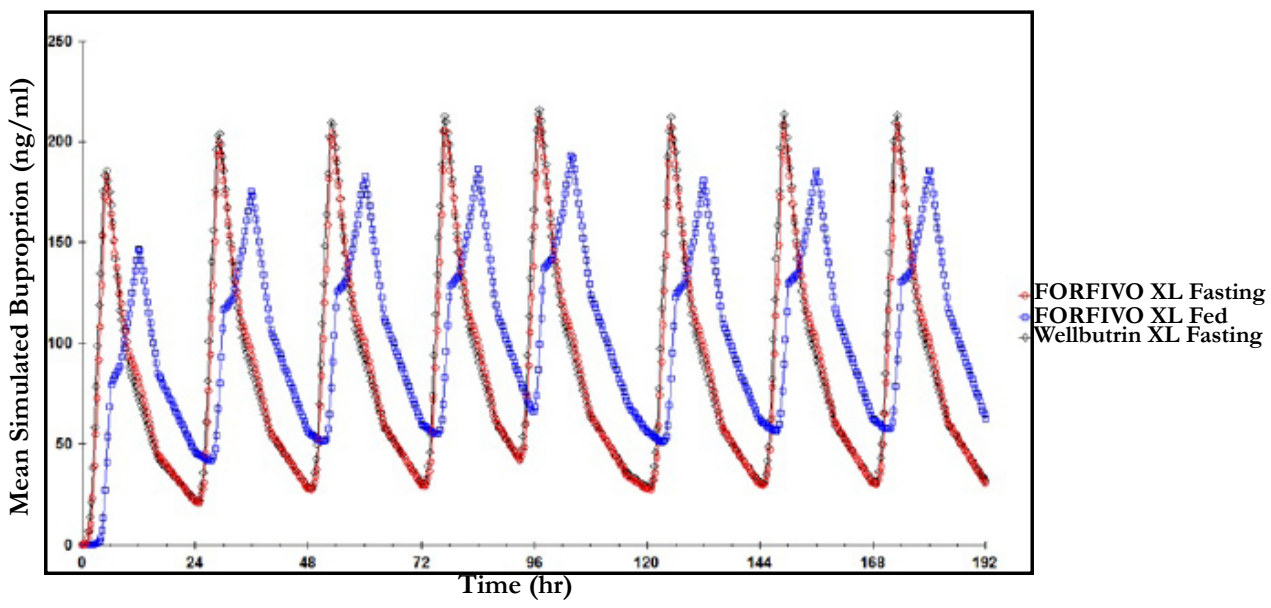

B

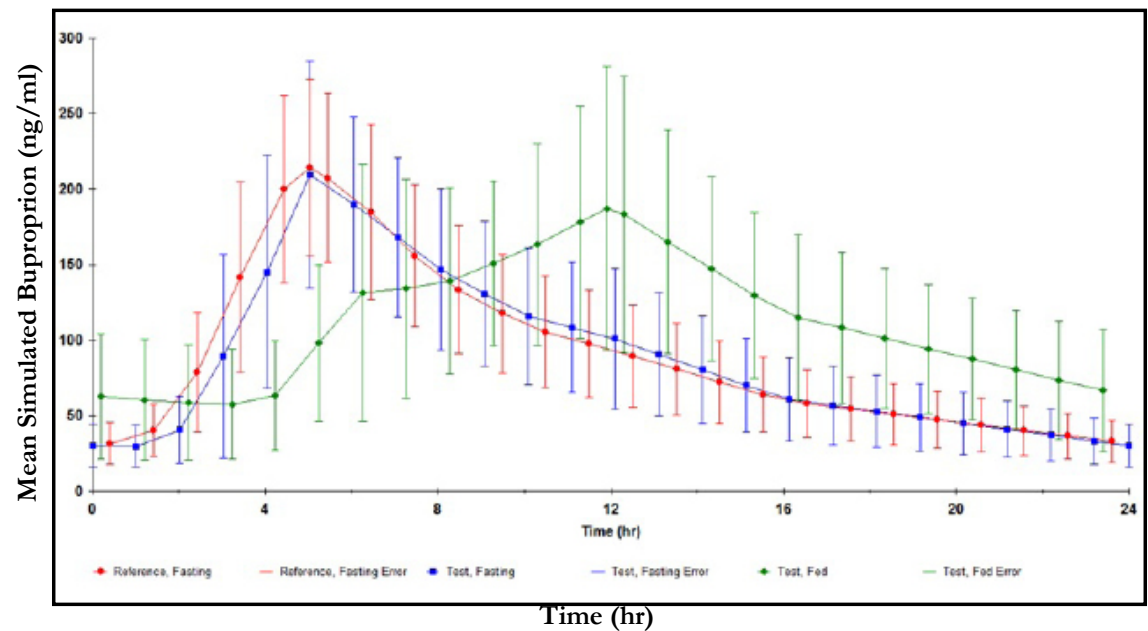


C

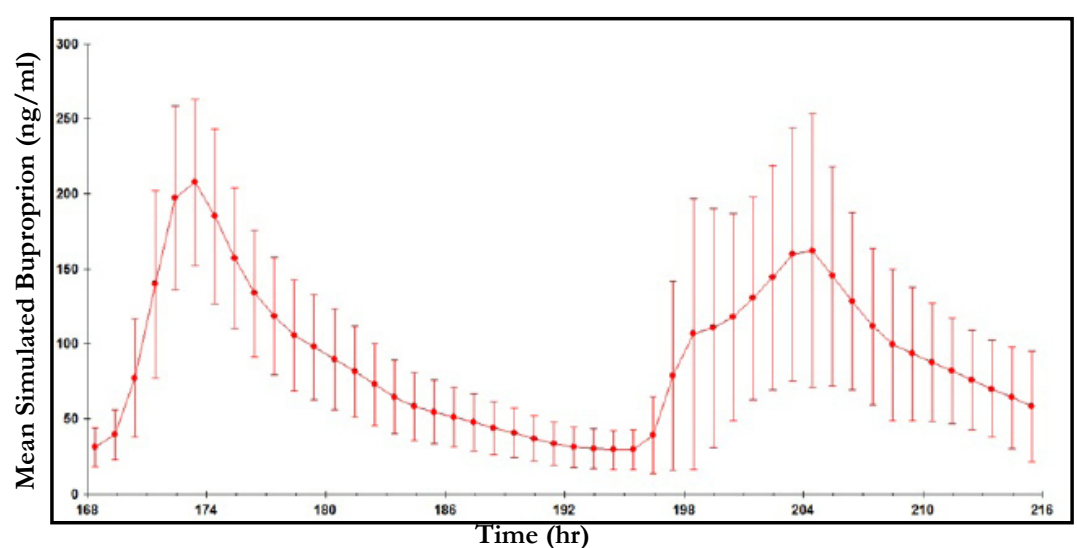

Table 1: Summary Statistics for Simulated Steady-State Bupropion PK Parameters and Ln transformed steady-state simulated bupropion data, Ratio (\% Ref) and $90 \%$ confidence intervals for $\mathrm{AUC}_{\text {last }}$ and $\mathrm{C}_{\mathrm{m}}$

\begin{tabular}{|c|c|c|c|c|c|c|c|c|c|}
\hline & \multicolumn{3}{|c|}{ 450ER Fasting } & \multicolumn{3}{|c|}{ 450ER Fed } & \multicolumn{3}{|c|}{ REF Fasting } \\
\hline & $\begin{array}{l}\mathrm{C}_{\max } \\
\text { (ng/mL) }\end{array}$ & $\begin{array}{l}T_{\max } \\
\text { (hr) }\end{array}$ & $\begin{array}{l}\mathrm{AUC}_{\tau} \\
\text { (hr*ng/mL) }\end{array}$ & $\begin{array}{l}\mathrm{C}_{\max } \\
(\mathrm{ng} / \mathrm{mL})\end{array}$ & $\begin{array}{l}T_{\text {max }} \\
\text { (hr) }\end{array}$ & $\begin{array}{l}\text { AUC }_{\tau} \\
(\mathrm{hr} * \mathrm{ng} / \mathrm{mL})\end{array}$ & $\begin{array}{l}\mathrm{C}_{\max } \\
(\mathrm{ng} / \mathrm{mL})\end{array}$ & $\mathbf{T}_{\text {max }}(\mathrm{hr})$ & $\begin{array}{l}\text { AUC } \\
(\mathrm{hr} * \mathrm{ng} / \mathrm{mL})\end{array}$ \\
\hline $\mathbf{N}$ & 35 & 35 & 35 & 35 & 35 & 35 & 35 & 35 & 35 \\
\hline Mean & 231 & 5.64 & 2140 & 249 & 10.99 & 2660 & 240 & 4.78 & 2170 \\
\hline SD & 66.5 & 2.04 & 659 & 80.6 & 4.23 & 703 & 58.9 & 0.81 & 566 \\
\hline Min & 103 & 3.03 & 862 & 102 & 0.00 & 1380 & 160 & 3.03 & 1230 \\
\hline Median & 234 & 5.04 & 2290 & 257 & 11.90 & 2620 & 237 & 4.84 & 2140 \\
\hline Max & 339 & 12.1 & 3290 & 441 & 24.00 & 4010 & 389 & 6.05 & 3330 \\
\hline CV\% & 28.8 & 36.1 & 30.8 & 32.3 & 38.5 & 26.4 & 24.5 & 17.0 & 26.1 \\
\hline 95\% CI Lower & 208 & 4.94 & 1910 & 222 & 9.536 & 2420 & 220 & 4.50 & 1980 \\
\hline 95\% CI Upper & 254 & 6.341 & 2360 & 277 & 12.441 & 2900 & 261 & 5.062 & 2370 \\
\hline
\end{tabular}

\begin{tabular}{|c|c|c|c|c|c|c|}
\hline & Dependent & Ref & Test & Ratio (\% Ref) & CI 90 Lower & CI 90 Upper \\
\hline \multirow[t]{2}{*}{$\begin{array}{l}\text { 450ER Fasting vs. } \\
\text { REF Fasting }\end{array}$} & $\begin{array}{l}\mathrm{Ln}\left(\mathrm{AUC}_{\tau}\right) \\
\left(\mathrm{hr}{ }^{*} \mathrm{ng} / \mathrm{mL}\right)\end{array}$ & 7.6486 & 7.6144 & 96.63 & 89.98 & 103.78 \\
\hline & $\begin{array}{l}\operatorname{Ln}\left(\mathrm{C}_{\max }\right) \\
(\mathrm{ng} / \mathrm{mL})\end{array}$ & 5.4538 & 5.3980 & 94.58 & 86.00 & 104.01 \\
\hline \multirow[t]{2}{*}{$\begin{array}{l}\text { 450ER Fed vs. } \\
\text { REF Fasting }\end{array}$} & $\begin{array}{l}\mathrm{Ln}\left(\mathrm{AUC} \mathrm{C}_{\text {r }}\right) \\
\left(\mathrm{hr}{ }^{*} \mathrm{ng} / \mathrm{mL}\right)\end{array}$ & 7.6486 & 7.8505 & 122.37 & 113.94 & 131.41 \\
\hline & $\begin{array}{l}\operatorname{Ln}\left(C_{\max }\right) \\
(\mathrm{ng} / \mathrm{mL})\end{array}$ & 5.4538 & 5.4656 & 101.19 & 92.02 & 111.28 \\
\hline
\end{tabular}

(fasting), 450ER (fed) and REF (fed). The two fasting treatments in this figure were nearly superimposable. This figure confirms that bupropion steady-state is achieved before Day 8. Because the extrapolated portions of the concentration-time curves are critical to the superposition approach, the fits were assessed by comparing the half lives derived from the nonparametric simulations with those determined from the noncompartmental analyses of the single dose data. The graphics provided in Figure 2 demonstrate excellent agreement between these half lives and confirm that the superposition approach provides reasonable estimates of steady-state concentrations.

The mean (SD) graphs of the simulated steady-state concentration time profiles for each of the three treatments are provided as Figure 1B. This figure illustrates that REF provides tighter control of plasma concentrations with lower peak to trough fluctuations. Summary statistics for the simulated steady-state $\mathrm{C}_{\max }, \mathrm{T}_{\max }$ and AUC values are provided in Table 1. Additionally Table 1 provides the corresponding
$90 \%$ confidence intervals of the ln-transformed individual ratios of $\mathrm{C}_{\max }$ and $\mathrm{AUC}_{\tau}$ for $450 \mathrm{ER}$ (fed and fasting) relative to REF (fasting).

The point estimates and confidence intervals from the steady-state simulations were similar to those reported in the single dose study where 450ER (fasting) was equivalent to REF (fasting). The Test/Ref point estimates for steady state AUC and $\mathrm{C}_{\max }$ were $96.63 \%$ and $94.58 \%$, respectively. The Test/Ref point estimates from the single dose BE study were $94.94 \%$ and $96.51 \%$, respectively and confidence intervals fell within $80.00 \%$ to $125.00 \%$. For the $450 \mathrm{ER}$ (fed) to REF (fasting) comparison, steady-state $\mathrm{C}_{\max }$ values were equivalent, but AUC was high, similar to the single dose study. The Test Fed/Ref point estimates for steady state AUC and $\mathrm{C}_{\max }$ were $122.37 \%$ and $101.19 \%$, respectively; the point estimates from the single dose BE study were $124.89 \%$ and $101.41 \%$, respectively. The confidence intervals for simulated steady-state AUC and $\mathrm{C}_{\max }$ were $113.94 \%$ to $131.41 \%$ and $92.02 \%$ to $111.28 \%$, respectively. The similarity in the statistics serves to validate these simulations. 
Figure 2: Correlation of half lives derived using noncompartmental analysis of single dose data (Study 1), and nonparametric simulations to derive predicted steady-state concentrations. Top, middle and bottom panels illustrate correlations for 450ER fasting, 450ER fed and REF fasting, respectively.
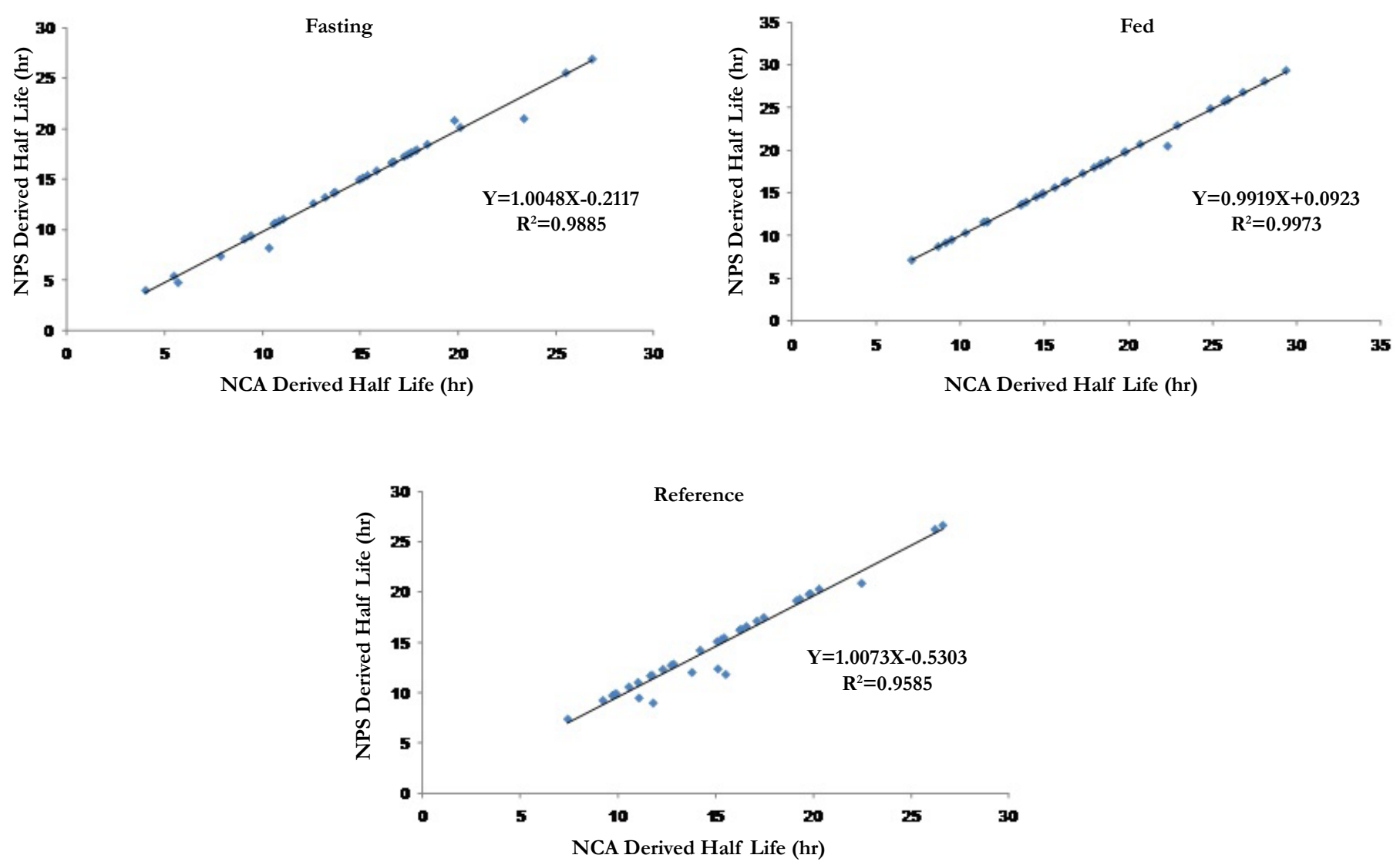

Table 2: Summary Statistics for Simulated Bupropion PK Parameters for REF after 8 Days of dosing and for 450ER after dosing on Day 9 , and Ln transformed data. Ratio (\% Ref) and $90 \%$ confidence intervals for $\mathrm{AUC}_{\text {last }}$ and $\mathrm{C}_{\max }$

\begin{tabular}{|l|l|l|l|l|l|l|}
\hline & \multicolumn{3}{|c|}{ Day 8 = REF Fasting } & \multicolumn{3}{c|}{ Day 9 450ER Fed } \\
\hline & $\begin{array}{l}\mathbf{C}_{\max } \\
(\mathbf{n g} / \mathbf{m L})\end{array}$ & $\begin{array}{l}\mathbf{T}_{\max } \\
(\mathbf{h r})\end{array}$ & $\begin{array}{l}\mathbf{A U C}_{\text {last }} \\
(\mathbf{h r} \text { (ng/mL) }\end{array}$ & $\begin{array}{l}\mathbf{C}_{\text {max }} \\
(\mathbf{n g} / \mathbf{m L})\end{array}$ & $\begin{array}{l}\mathbf{T}_{\text {max }} \\
(\mathbf{h r})\end{array}$ & $\begin{array}{l}\mathbf{A U C}_{\text {last }} \\
(\mathbf{h r} \text { *ng/mL) }\end{array}$ \\
\hline $\mathbf{N}$ & 35 & 35 & 35 & 35 & 35 & 35 \\
\hline Mean & 240 & 4.8 & 2160 & 237 & 11.9 & 2200 \\
\hline SD & 59.0 & 0.8 & 556 & 82.2 & 4.8 & 606 \\
\hline Min & 160 & 3.0 & 1220 & 78.0 & 6.1 & 940 \\
\hline Median & 238 & 5.0 & 2140 & 241 & 12.1 & 2130 \\
\hline Max & 394 & 6.0 & 3320 & 435 & 24.1 & 3190 \\
\hline CV\% & 24.5 & 17.0 & 25.8 & 34.7 & 40.0 & 27.6 \\
\hline $\mathbf{9 5 \% ~ C I ~ L o w e r ~ M e a n ~}$ & 220 & 4.5 & 1970 & 209 & 10.3 & 1990 \\
\hline 95\% CI Upper Mean & 261 & 5.1 & 2350 & 265 & 13.6 & 2400 \\
\hline
\end{tabular}

$\mathrm{AUC}_{\text {last }}=\mathrm{AUC}_{\text {tau }}$

\begin{tabular}{|l|l|l|l|l|l|}
\hline Dependent & Ref & Test & $\begin{array}{l}\text { Ratio } \\
\text { (\% Ref })\end{array}$ & $\begin{array}{l}\text { CI } \\
\text { 90 Lower }\end{array}$ & $\begin{array}{l}\text { CI } \\
\text { 90 Upper }\end{array}$ \\
\hline $\begin{array}{l}\text { Ln(AUC } \\
(\mathrm{hr} \text { last })\end{array}$ & 7.6444 & 7.6544 & 101.01 & $\mathbf{9 0 . 3 6}$ & $\mathbf{1 1 2 . 9 0}$ \\
\hline $\begin{array}{l}\mathrm{Ln}\left(\mathrm{C}_{\max }\right) \\
(\mathrm{ng} / \mathrm{mL})\end{array}$ & 5.4534 & 5.3981 & 94.62 & $\mathbf{8 2 . 8 6}$ & $\mathbf{1 0 8 . 0 5}$ \\
\hline
\end{tabular}


Figure 3: Mean plasma concentrations of 450ER after administration of $450 \mathrm{mg}$ as REF $3 \times 150 \mathrm{mg}$ tablets to healthy volunteers under fed and fasted conditions

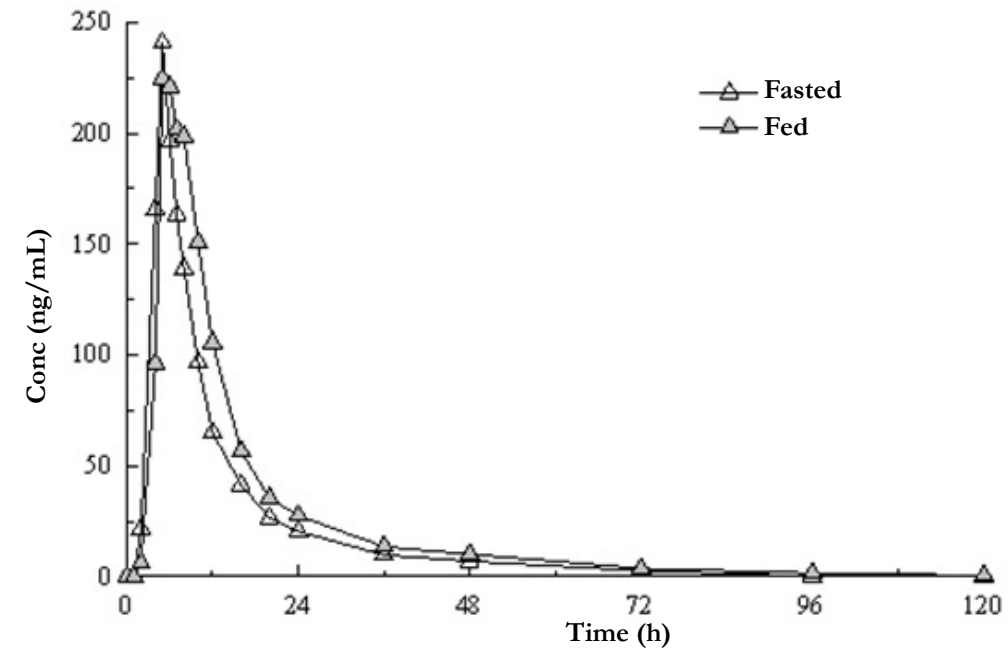

Table 3: Summary of statistical analysis (Study 2), REF (fed) vs REF (fasted), Bupropion, N=9

\begin{tabular}{|c|c|c|c|c|c|c|c|c|c|}
\hline \multicolumn{10}{|c|}{ Ln-Transformed data } \\
\hline \multirow{2}{*}{$\begin{array}{l}\text { PK } \\
\text { Variable }\end{array}$} & \multicolumn{2}{|c|}{ Least Squares Mean } & \multicolumn{3}{|c|}{ Geometric mean } & \multirow{2}{*}{\begin{tabular}{|l}
$90 \%$ Confidence \\
interval
\end{tabular}} & \multirow{2}{*}{$\begin{array}{l}\text { P-values } \\
\text { for product } \\
\text { effects }\end{array}$} & \multirow{2}{*}{$\begin{array}{l}\text { Power of } \\
\text { ANOVA }\end{array}$} & \multirow{2}{*}{$\begin{array}{l}\text { ANOVA } \\
\% \mathrm{CV}\end{array}$} \\
\hline & Ref-Fed & Ref-Fast & Ref-Fed & Ref-Fast & $\%$ Ratio & & & & \\
\hline $\mathrm{C}_{\max }$ & 5.43 & 5.513 & 228.15 & 247.77 & 92.08 & $64.6,131.26$ & 0.6727 & 0.1788 & 41.04 \\
\hline $\mathrm{AUC}_{0-\mathrm{t}}$ & 7.908 & 7.677 & 2718.01 & 2157.22 & 126.00 & $99.99,158.76$ & 0.1001 & 0.3526 & 26.15 \\
\hline $\mathrm{AUC}_{0 \text {-inf }}$ & 7.947 & 7.721 & 2825.71 & 2255.09 & 125.30 & $100.1,156.85$ & 0.0987 & 0.3697 & 25.38 \\
\hline
\end{tabular}

\begin{tabular}{|c|c|c|c|c|c|c|}
\hline \multicolumn{7}{|c|}{ Non-Transformed Data } \\
\hline \multirow{2}{*}{$\begin{array}{l}\text { PK } \\
\text { Variable }\end{array}$} & \multicolumn{3}{|c|}{ Least Squares Mean } & \multirow{2}{*}{\begin{tabular}{|l|}
$90 \%$ Confidence interval \\
P-values for product effects \\
\end{tabular}} & \multirow{2}{*}{$\begin{array}{l}\text { P-values for } \\
\text { product effects }\end{array}$} & \multirow{2}{*}{$\begin{array}{l}\text { Power of } \\
\text { ANOVA }\end{array}$} \\
\hline & Ref-Fed & Ref-Fast & $\%$ Ratio & & & \\
\hline $\mathrm{C}_{\max }$ & 251.65 & 253.78 & 99.16 & $61.11,137.22$ & 0.9679 & 0.1391 \\
\hline $\mathrm{AUC}_{0-\mathrm{t}}$ & 2851.12 & 2177.26 & 130.95 & $102.24,157.76$ & 0.0805 & 0.2083 \\
\hline $\mathrm{AUC}_{0 \text {-inf }}$ & 2957.68 & 2273.75 & 130.08 & $102.4,157.76$ & 0.0785 & 0.2205 \\
\hline $\mathrm{T}_{\max }$ & 6.25 & 5.4 & 115.74 & $85.64,145.84$ & 0.3548 & 0.1938 \\
\hline Kel & 0.0468 & 0.0465 & 100.51 & $90.2,110.7$ & 0.9270 & 0.8882 \\
\hline $\mathrm{T}_{1 / 2}$ & 19.34 & 17.84 & 108.40 & $95.93,120.87$ & 0.2424 & 0.7414 \\
\hline
\end{tabular}

The point estimates and confidence intervals from this simulation, as listed in Table 2, predict that both $\mathrm{C}_{\max }$ and AUC were bioequivalent. That is, on the initial day when a patient is switched from REF $(3 \times 150 \mathrm{mg}$, while fasting) to 450ER (450 mg with food), the predicted $\mathrm{C}_{\max }$ and $\mathrm{AUC}$ values will be bioequivalent. The Test/Ref point estimates for AUC and $\mathrm{C}_{\mathrm{m}}$ were $101.01 \%$ and $94.62 \%$, respectively; the confidence intervals for AUC and $\mathrm{C}_{\max }$ were $90.36 \%$ to $112.90 \%$ and $82.86 \%$ to $108.05 \%$, respectively.

\section{Conclusion}

The results show that the $90 \%$ confidence intervals for ln-transformed $\mathrm{AUC}_{\text {tau }}$ and $\mathrm{C}_{\max }$ values on Day 9 (after switching to 450ER) relative to day 8 (steady-state REF before switching) are within the $80-125 \%$ bioequivalence acceptance range. This predicts that switching from a steady-state dosing regimen of $3 \times 150 \mathrm{mg}$ REF tablets to 450ER taken with food will not result in significantly increased AUC or $\mathrm{C}_{\max }$ levels. These simulations support the equivalence of 450ER and REF and that a switch from REF in patients who take the product in the fasting state to 450ER if taken with food (the worst case scenario) does not significantly increase bupropion exposure and therefore, does not expose patients to elevated risk of seizures. When patients switch from REF to 450ER fasting, the two products would also be bioequivalent as demonstrated by the single-dose study.

Although the professional labeling for REF states that food did not affect the $\mathrm{C}_{\max }$ or AUC of bupropion, data generated in the single dose study demonstrated that there is a small food effect that is similar in these two products (REF and 450ER). Observed $\mathrm{C}_{\text {max }}$ and AUC values are provided in Table 3. Figure 3 illustrates the mean bupropion concentrations obtained after administration of REF when fasting or after a standard FDA meal. The Test/Ref (Fed/Fasting) point estimates for REF bupropion AUC and $\mathrm{C}_{\max }$ were $125.30 \%$ and $92.08 \%$, respectively. In the most recent 450ER study (Study 1), the Fed/Fasting bupropion point estimates for AUC and $\mathrm{C}_{\max }$ were $124.89 \%$ and 
$101.41 \%$, respectively. Thus, the extent of absorption for both 450ER and REF increases by $25 \%$ when the products are dosed with food, relative to the fasting state. Given the safety experience with REF, this increase in exposure is not clinically relevant.

\section{References}

[1]. Anthony w. Peck, Warren C. Stern, Catherine Watkinson, Incidence of seizures during treatment with tricyclic antidepressant drugs and bupropion. J. Clin. Psychiatry. 1983; 44:5(Sec 2):197-201

[2]. James W. Jefferson, James F. Pradko, Keith T. Muir, Bupropion for major depressive disorder: pharmacokinetic and formulation considerations. Clinical Therapeutics, 2005; 27(11):1685-1695

[3]. Maurezio Fava, John Rush, Michael E Thase et al. 15 years of experience with bupropion $\mathrm{HCl}$ : from bupropion to bupropion SR to bupropion XL. 2005; J. Clin Psychiatry, 7(3):106-113

[4]. Dunner DL, Zisook S, Billow AA et al. A prospective safety surveillance study for bupropion sustained-release in the treatment of depression. J Clin Psychiatry. 1998;59(7):366-73

[5]. Aplenzin ${ }^{\circledR}$ prescribing information, http://products.sanofi.us/ aplenzin/aplenzin.pdf 